\section{A modalização epistêmica asseverativa na construção argumentativa de entrevistas de seleção de emprego}

\author{
Asseverative epistemic \\ modalization in the \\ rgumentative construction \\ of employment selection \\ interviews
}

Francisca Janete da Silva ADELINO (UFPB) janete_adelino@hotmail.com

Erivaldo Pereira do NASCIMENTO (UFPB) erypn@hotmail.com

Recebido em: 12 de ago. de 2018. Aceito em: 03 de jan. de 2019.

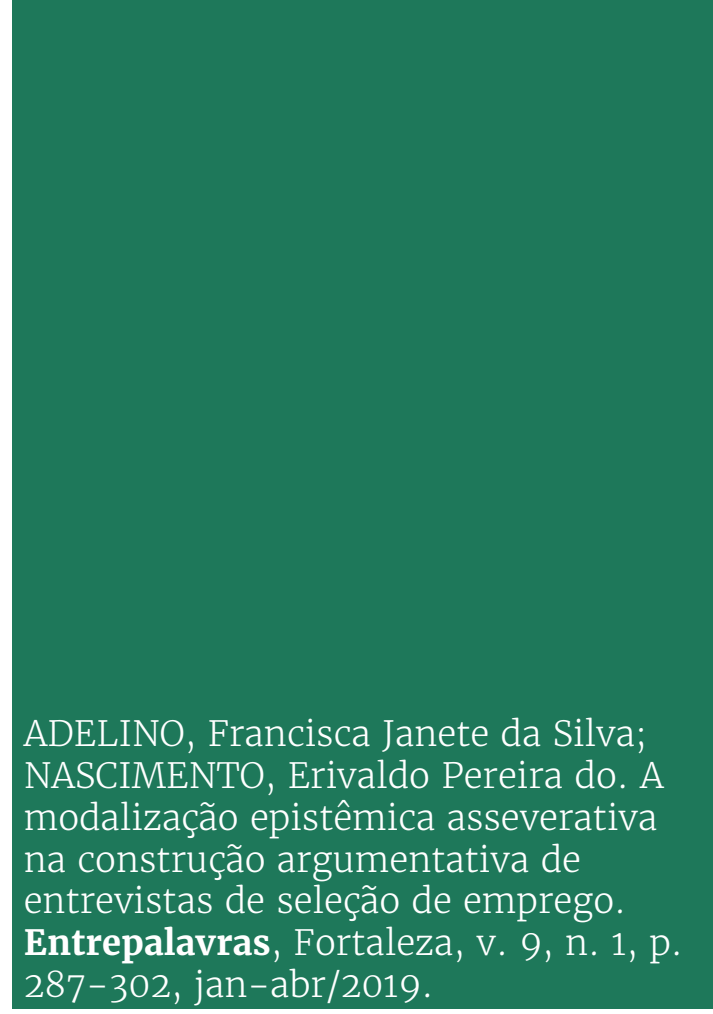

Resumo: A relação entre elementos da língua e a argumentação é concebida, no âmbito da Linguística, como sendo de natureza inseparável. Neste trabalho, objetivamos investigar o funcionamento argumentativo dos modalizadores epistêmicos asseverativos na construção do gênero entrevista de seleção de emprego, a partir da análise de um corpus composto por vinte e duas entrevistas de seleção de emprego. Para tal, fundamentamo-nos nos estudos sobre a Modalização Discursiva, a partir de Lyons (1977), Palmer (2001), Castilho e Castilho (2002), Koch (2010) e Nascimento e Silva (2012), além dos estudos sobre a argumentação linguística de Ducrot (1988). A análise mostra o funcionamento argumentativo dos modalizadores epistêmicos asseverativos nos pontos de marcação de um comprometimento tanto por parte do entrevistador quanto por parte do entrevistado em relação ao dito. Tais modalizadores avaliam os ditos como incontestáveis, criando a imagem de um locutor comprometido e engajado com o conteúdo de seu dizer. Ademais, a argumentatividade das entrevistas não foi gerada apenas pela utilização de determinadas palavras e expressões, que imprimem o caráter de certeza 
V. 9 (1)

287-302

jan-abr

2019

no enunciado, mas também pelo recurso da entonação de ênfase e pelo recurso da repetição, os quais funcionaram como modalizadores asseverativos em alguns enunciados proferidos pelos entrevistadores (L1) e pelos entrevistados (L2).

Palavras-Chave: Argumentação na língua. Modalização epistêmica asseverativa. Argumentação.

\begin{abstract}
The relationship between language elements and argumentation is conceived as being of indivisible nature, within the scope of Linguistics. In this article, we aim to investigate the argumentative function of the asseverative epistemic modalizers in the construction of employment selection interview genre, based on the analysis of a corpus composed of twenty - two employment selection interviews. It is also based on the studies about Discursive Modality proposed by Lyons (1977), Palmer (2001), Castilho \& Castillho (2002), Koch (2010) and Nascimento \& Silva (2012), as well as the study about linguistic argumentation by Ducrot (1988). The analysis reveals the argumentative function of the asseverative epistemic modalizers in the marking points of a commitment both by the interviewer and by the interviewee in relation to what was said. Such modalizers evaluate the sayings as incontestable, creating the image of a locutor committed and engaged with the content of its saying. Moreover, the argumentativeness of the interviews was not only generated by the use of certain words and expressions, which express the character of certainty in the statement, but also by the emphasis intonation resource and by the repetition resource, which functioned as assertive modalizers in some statements made by the interviewers (L1) and interviewees (L2).
\end{abstract}

Keywords: Argumentation in language. Asseverative epistemic modalization. Argumentation.

\title{
Introdução
}

Embora a relação entre elementos da língua e a argumentação tenha, ao longo dos séculos, chamado a atenção de diferentes áreas do conhecimento, como a Filosofia e a Lógica, é na Linguística, conforme comenta Adelino (2016), que encontramos estudos que tornam essa relação inseparável. É com Ducrot (1988) que a língua é estudada como apresentando uma natureza argumentativa. Para esse estudioso, a língua é fundamentalmente argumentativa e a argumentatividade gerada pelo funcionamento de determinados elementos linguísticos vai da língua ao discurso, permitindo determinadas orientações e conclusões. Assim, não só a língua, mas também o uso que dela fazemos é argumentativo, como acrescenta Espíndola (2004).

Partindo dessa perspectiva e centrando o olhar, principalmente, nos estudos sobre a Modalização Discursiva, desenvolvidos por Lyons (1977), Palmer (2001), Castilhoe Castilho(2002), Koch (2010), Nascimento e Silva (2012), entre outros, objetivamos investigar o funcionamento argumentativo dos modalizadores epistêmicos asseverativos na construção do gênero entrevista de seleção de emprego. 
Esse gênero, segundo Adelino (2016), faz parte do universo empresarial e é utilizado, principalmente, por profissionais da área de Recursos Humanos para aprofundar questões relacionadas às competências e habilidades de candidatos à vaga de emprego, em processos de recrutamento e seleção de pessoal.

Nesta investigação, a modalização é tomada como um fenômeno que permite ao locutor deixar registrado, no seu discurso, marcas de sua subjetividade através de determinados elementos linguísticos e, portanto, imprimir um modo como esse discurso deve ser lido, funcionando, assim, como uma estratégia semântico-argumentativa e pragmática, conforme a perspectiva usada por Nascimento e Silva (2012).

No tocante aos aspectos metodológicos, apresentamos um recorte da nossa pesquisa de doutorado, na qual trabalhamos com um corpus composto de 22 (vinte e duas) entrevistas de seleção de emprego gravadas em áudio durante o processo de seleção de professores para os cursos técnicos de Logística, Radiologia e Vigilância em Saúde, em um Centro Universitário do Estado do Rio Grande do Norte, na cidade de Natal - RN. A transcrição do corpus foi realizada com base no Projeto de Estudo da Norma Urbana Linguística Culta (PROJETO NURC) Brasil.

A investigação assume uma abordagem qualitativa devido à natureza do trabalho, que é a identificação e a interpretação dos modalizadores epistêmicos asseverativos presentes no gênero. Assume, ainda, um caráter descritivo de base interpretativa, porque procuramos descrever o funcionamento argumentativo do fenômeno da modalização, à luz do referencial teórico adotado.

A fim de facilitar a leitura e a identificação dos modalizadores materializados no corpus, na análise, os recortes aparecem codificados. Essa codificação, realizada por ocasião da catalogação do corpus, inclui o tipo de modalizador, a entrevista de seleção de emprego da qual extraímos o modalizador e as linhas transcritas da entrevista. Por exemplo, na codificação MEA100 - EE17 - Linhas 95-100, a sigla MEA10o corresponde ao Modalizador Epistêmico Asseverativo 100. Essa numeração - 100 - corresponde à sequência do modalizador catalogado no corpus da pesquisa original. Já a sigla EE17 corresponde à Entrevista de Seleção de Emprego de número 17, conforme ordem atribuída a cada entrevista coletada e Linhas 95-100 dizem respeito às linhas da entrevista transcrita. Além disso, L1 representa o entrevistador e L2 o entrevistado. 
V. 9 (1)

287-302

jan-abr 2019

Por sua vez, o nome do Centro Universitário no qual realizamos a coleta dos dados não será revelado, tendo em vista o compromisso que assumimos junto ao Conselho de Ética. Assim, usamos o nome fictício denominado de Unixy.

Este artigo se encontra organizado em três tópicos principais, além da introdução e da conclusão. No primeiro tópico, apresentamos uma breve discussão acerca da Modalização Discursiva, focalizando a modalização epistêmica asseverativa. No segundo tópico, tratamos do gênero discursivo entrevista de seleção de emprego. E, no terceiro tópico, discutimos o uso argumentativo da modalização epistêmica asseverativa na construção de sentidos do gênero entrevista de seleção de emprego.

\section{O fenômeno da modalização: notas sobre a modalização epistêmica asseverativa}

O fenômeno da modalização institui um dos tipos de manifestação da subjetividade da/na linguagem, sendo ainda constitutiva da significação dos enunciados, de modo que as marcas de subjetividade estão impressas em determinados elementos linguísticos (os modalizadores). Eles traduzem um maior ou menor comprometimento do locutor em relação ao conteúdo enunciado. O compromisso assumido pelo locutor, no ato do enunciado, permite situar o papel da subjetividade na construção do discurso.

Os modalizadores permitem ainda, conforme Nascimento (2010), orientar o sentido dos enunciados em razão de determinadas conclusões, indicando possíveis leituras para o interlocutor (marca de intersubjetividade). Nesse sentido, se constituem em elementos indicadores de argumentação, uma vez que imprimem, no sentido do enunciado, a subjetividade e a intersubjetividade. Dessa forma, convém ressaltar, como afirma Ducrot (1988), que a subjetividade e a intersubjetividade são aspectos intrinsecamente relacionados e se constituem no valor semântico e argumentativo dos enunciados.

Existem vários tipos de modalizadores, por exemplo, os deônticos, os volitivos, os avaliativos e os epistêmicos. Esses modalizadores se realizam em subcategorias. Assim, para Nascimento e Silva (2012) a modalização epistêmica se subdivide em epistêmica asseverativa, epistêmica quaseasseverativa e epistêmica habilitativa. Diante da necessidade de um recorte e considerando o objetivo deste artigo, focalizamos a discussão em torno dos modalizadores epistêmicos asseverativos. 
A modalidade epistêmica, de acordo com Lyons (1977), está relacionada ao conhecimento ou crença do falante em relação à verdade de uma proposição. Portanto, um enunciado epistemicamente modalizado é aquele em que o falante qualifica explicitamente seu comprometimento com relação à verdade da proposição.

Na visão de Palmer (2001), esta modalidade indica o grau de comprometimento do falante no que diz respeito à evidência ou fonte do que se diz, assim como os julgamentos, opiniões ou conclusões do falante. Nessa mesma perspectiva, Castilho e Castilho (2002) asseveram que esse tipo de modalidade ocorre quando o falante expressa uma avaliação sobre o valor de verdade e as condições de verdade da proposição.

Ao fazer uso da modalização epistêmica asseverativa, o locutor apresenta sua proposição considerando seu conteúdo verdadeiro. Nesse caso, o locutor exclui todas as possibilidades de dúvidas, constituindose numa necessidade epistêmica. A utilização de modalizadores asseverativos visa criar, portanto, determinados efeitos de sentidos, como o de enfatizar o conteúdo proposicional. Com isso, o valor de verdade e de certeza construído na troca comunicativa se constitui um forte instrumento argumentativo entre os interlocutores.

Conforme Castilho e Castilho (2002), ao lançar mão de modalizadores asseverativos, o falante objetiva expressar uma alta adesão ao conteúdo da proposição, ao mesmo tempo em que acentua a subjetividade no/do discurso. Nesse caso, a marcação de um maior engajamento do locutor com o enunciado se configura recurso argumentativo. E o locutor constrói uma relação pessoal com o interlocutor, tornando a comunicação um espaço de envolvimento pessoal-subjetivo.

Ao investigar o valor argumentativo dos modalizadores epistêmicos asseverativos, Castilho e Castilho (2002) ressaltam que este recurso é utilizado pelo locutor para valorizar a própria fala e também para asseverar a disposição do falante em sustentar o conteúdo da proposição. Além disso, em algumas situações, a asseveração se desloca do âmbito da proposição para o âmbito da situação de comunicação, revelando, assim, o caráter interativo e social desses modalizadores.

Ademais, os asseverativos geralmente são construídos sobre uma base adjetiva. Os advérbios asseverativos exatamente, claramente, certamente, logicamente e prontamente, por exemplo, são construídos, respectivamente, a partir dos adjetivos exato, claro, certo, lógico e 
V. 9 (1)

287-302

jan-abr 2019

pronto, conforme estudos de Castilho e Castilho (2002). Com isso, os modalizadores epistêmicos asseverativos podem, além de enfatizar o conteúdo da proposição do locutor, avaliar e asseverar a fala do outro, mantendo, desse modo, o diálogo entre os interlocutores.

Tal aspecto assinala que os asseverativos podem ser mobilizados para comentar e/ou avaliar o conteúdo proposicional dito por um outro. Isso é possível porque, afirma Castilho e Castilho (2002, p. 227), "as propriedades semântico-pragmáticas desses asseveradores permitem sua utilização como demarcadores de unidades discursivas".

Nascimento e Silva (2012), no que diz respeito aos modalizadores asseverativos, concordam com os postulados de Castilho e Castilho (2002) e complementam essa discussão. Para ilustrar esse tipo de modalização, eles utilizam o seguinte exemplo: Com certeza haverá aula hoje. Segundo Nascimento e Silva (2012), o predicativo com certeza apresenta o conteúdo do enunciado como um conhecimento, uma certeza.

Nesse caso, o locutor se compromete, ou seja, assume a responsabilidade pelo dito. Além disso, quanto ao movimento argumentativo, o locutor imprime o modo como o seu enunciado deve ser lido pelo interlocutor. Portanto, a modalização epistêmica asseverativa "funciona como uma estratégia argumentativo-pragmática bastante eficaz" (NASCIMENTO \& SILVA, 2012, p. 81).

Dito isso, faremos agora uma breve discussão acerca da entrevista de seleção de emprego, considerando seu funcionamento enquanto modo de interação social e finalidade discursiva.

\section{Gênero entrevista de seleção de emprego}

Esse gênero, segundo Adelino (2016), faz parte do universo empresarial e é utilizado, principalmente, por profissionais da área de Recursos Humanos para aprofundar questões relacionadas às competências e habilidades de candidatos à vaga de emprego, em processos de recrutamento e seleção de pessoal.

Conforme entende Lodi (1991), a entrevista de emprego visa coletar informações sobre o entrevistado e, em função desse caráter, deve ser previamente planejada. Nesse gênero, o entrevistador tem a função de maximizar o fluxo de informações relativas ao histórico profissional do entrevistado e, para tanto, deve interpretar antecipadamente documentos, tais como currículo, ficha e resultado de testes com o propósito de garantir a eficácia do processo seletivo. 
Lodi (1991) acrescenta que a entrevista é comumente estabelecida na forma de diversos funis, de modo que, em cada tópico, a primeira pergunta deve ser mais abrangente, a segunda mais específica e, assim, sucessivamente, até estreitar o escopo e esgotar aquele tópico. Há casos, entretanto, em que a sequência é um funil ao inverso, começando com uma pergunta mais específica para outra mais ampla.

Nessa perspectiva, a entrevista de seleção de emprego pode ser tomada como um instrumento de comparação no processo de recrutamento e seleção. Para tanto, o entrevistador "[...] precisa trabalhar dentro de certa precisão (apresentando resultados coerentes) e validade (medindo exatamente aquilo que se pretende verificar), tal como um instrumento de medida confiável" (CHIAVENATO, 2004, p. 198). Chiavenato (2004, p. 195) afirma que, durante a entrevista de seleção de emprego,

[...] dependendo das habilidades do entrevistador pode-se darlhe menor ou maior liberdade na condução da entrevista, isto é, pode-se estruturar e padronizar a entrevista, como podese deixá-la inteiramente livre à sua vontade (CHIAVENATO, 2004, p.195).

A entrevista é uma interação assimétrica. Ela é assim entendida porque é o entrevistador que, comumente, direciona o desenvolvimento de tal interação, fazendo questionamentos ao entrevistado. Logo, é a partir da ação daquele que busca informações (o entrevistador) que a entrevista é conduzida.

O diálogo assimétrico, portanto, ocorre justamente pela relação de desigualdade existente entre os membros participantes de um evento de fala. Essa desigualdade diz respeito aos papéis, às funções, aos lugares ocupados por cada interlocutor envolvido na construção da entrevista. Um é o lugar do entrevistador; outro é o lugar do entrevistado.

Espíndola (2004) acrescenta que nessa modalidade de interação, incluem-se as entrevistas de modo geral. Para essa estudiosa, a entrevista pertence à classe dos discursos institucionalizados assimétricos porque a maioria dos parâmetros reguladores do discurso institucionalizado aponta para esse resultado.

Fávero (2000) argumenta que a entrevista é um tipo especial de texto falado porque há normalmente um planejamento prévio por parte do entrevistador. Para a autora, o objetivo da entrevista "[...] é sempre o interrelacionamento humano, mas os direitos dos participantes não são os mesmos, pois o entrevistador faz as perguntas e oferece, em seguida, o turno ao entrevistado" (FÁVERO, 2000, p. 79). 
V. 9 (1)

287-302

jan-abr

2019

Segundo essa mesma pesquisadora, esse gênero possui características comuns às da atividade conversacional espontânea, ou seja, das interações casuais. No entanto, difere em vários aspectos desse tipo de texto exatamente por apresentar características próprias, tais como o planejamento prévio dos tópicos a serem desenvolvidos durante o evento, o par "pergunta-resposta" e a assimetria, em que um dos participantes exerce o direito de iniciar, orientar, dirigir e concluir o tópico.

Ao discutir sobre a entrevista, Marcuschi (1998) entende esse gênero como um método de investigação sob uma forma estruturada de conversação, cujo propósito é obter informações a partir do uso de tópicos relativos ao objeto da entrevista. Assim, "[...] os tópicos são sugeridos pelo entrevistador que deve criar condições de responsabilidade ao seu entrevistado. É assim que o entrevistador não apenas deve indagar, mas situar sua indagação num quadro de expectativas" (MARCUSCHI, 1998, p. 21). Portanto, a entrevista, enquanto gênero textual oral, faz parte dos eventos institucionalizados porque nesse evento há objetivos e tema determinados.

\section{Modalizadores epistêmicos asseverativos na construção argumentativa de entrevistas de seleção de emprego}

Apresentamos, a seguir, a análise de alguns trechos do corpus estudado, a fim de demonstrar não só a ocorrência dos modalizadores epistêmicos asseverativos presentes no gênero entrevista de seleção de emprego, mas, sobretudo, os efeitos de sentido que geram nos enunciados em que aparecem.

\section{MEA100-EE17-Linhas 95-100}

[...] L1 e já tá terminando a reforma... provavelmente a gente vá pra lá o semestre
que vem... não sei se no iniciozinho... mas a gente vai começar a se mudar... não
só a escola técnica... mas parte da graduação também... então já tenho certeza...
foi avisado ontem... então... é cem por cento de certeza de que o curso técnico de
logística vai... e aí eu tô avisando isso porque existe também essa questão... desse
trajeto né? desse deslocamento...

No trecho MEA10o, L1, ao explicar que o curso de Logística será transferido para outra unidade da instituição, que se encontra em reforma, assevera que tem certeza dessa transferência e procura deixar o seu enunciado mais claro ao afirmar que tem cem por cento de certeza. L1 apresenta essa informação como certa e põe força na asseveração, recorrendo a dois modalizadores de caráter asseverativo para não deixar margem para dúvidas. 
Na interação entre os participantes da entrevista, a informação em questão era necessária e importante para L2, já que esse precisava ter ciência disso, pois, caso fosse aprovado na seleção, ele teria que fazer outro percurso para chegar até o novo local de funcionamento do curso.

Cabe lembrar que o modalizador epistêmico asseverativo, segundo Castilho e Castilho (2002), avalia o valor e as condições de "verdade" da proposição. No caso em análise, o entrevistador constrói um discurso pautado na certeza, sem relativizações. E, conforme explicações de Nascimento e Silva (2012), modalizadores como com certeza apresentam o conteúdo do enunciado como um conhecimento, uma certeza, fazendo com que o locutor se comprometa com o dito, ou seja, assuma a responsabilidade pelo enunciado.

\title{
MEA116- EE22-Linhas 22-33
}

\begin{abstract}
[...] L2 então... isso:: essa prática me fez... me fez pensar em algumas estratégias pra trazer o aluno pra dentro da disciplina de língua portuguesa... criar esse diálogo... demonstrar a importância da língua portuguesa pra qualquer que seja a área...

L1 essa seria então a:: a minha próxima pergunta seria exatamente isso... qual a contribuição que você poderia dá pra o nosso curso? (...)

L2 é exatamente essa... assim... é:: a primeira coisa que penso... é:: é:: no planejamento do curso... quando diz assim... espero isso de você... eu já penso no link... é:: de como como fazer com que os alunos tenham acesso a isso... e mos... e mostrando pra eles... provando é:: de que maneira a língua portuguesa é importante pra carreira deles... pra pra vida acadêmica pra VIda acadêmica e profissional deles...
\end{abstract}

No trecho MEA116, L1 deixa explícito que L2 antecipou em sua fala uma questão que faria parte da pergunta seguinte da entrevista. Isso fica evidente quando L1 enuncia que: essa seria então a:: a minha próxima pergunta seria exatamente isso... qual a contribuição que você poderia dá pra o nosso curso? [...]. Ao usar o advérbio exatamente, L1 imprime um caráter exato, certo, no seu enunciado. É, também, um recurso que permite L1 retomar as ideias de L2. Esse, por sua vez, toma a palavra e também usa o mesmo advérbio antecedido do verbo ser (é), para confirmar o que já vinha afirmando anteriormente a respeito de algumas estratégias que usa no decorrer de suas aulas, visando [...] criar esse diálogo... demonstrar a importância da língua portuguesa pra qualquer que seja a área [...].

Embora os locutores façam uso do mesmo modalizador, não temos as mesmas valorações e direções argumentativas. Ao fazer uso do modalizador, L2 deixa claro que pode aplicar estratégias com os alunos do curso técnico em Logística, na disciplina de língua portuguesa, para a qual ele se candidatou. Na intenção de convencer seu interlocutor, ele se compromete com a veracidade do conteúdo do dito, ou seja, ao lançar mão do modalizador asseverativo em análise, L2 objetiva expressar uma alta adesão ao conteúdo da proposição. 
V. 9 (1)

287-302

jan-abr 2019

\section{MEA03-EE01-Linhas 41-45}

L2 [...] então passei pela área de cirurgia... pela área clínica... pela área de anestesia.. $(\ldots)$

L1 pela área de... radiologia?

L2 pela área de radiologia TAMbém... e... fui fazer o meu mestrado assim que acabei a faculdade na farmacologia né?

Nessa parte da entrevista, L2 apresenta um relato a respeito da sua experiência profissional na área da docência e defende o argumento de que já atuou nas áreas de cirurgia, anestesia e clínica. Ao ser interrompido por L1, que almeja saber sobre a sua experiência em radiologia, L2 prontamente afirma que também já passou por essa área. Podemos perceber que L2 defende o seu ponto de vista e sustenta com bastante segurança a experiência acumulada no decorrer da sua atuação profissional.

No caso em análise, constatamos a materialização da assimetria: L1 corta o fluxo de fala de L2 para perguntar se esse passou pela área de radiologia. Seguindo a estrutura relativamente estável do gênero entrevista de emprego, cabe ao entrevistador fazer esse tipo de intromissão. Koch (2010, p. 80) nos diz que nas interações assimétricas, como entrevistas, "um dos parceiros detém o poder da palavra e a distribui de acordo com a sua vontade". A entrevista é assim entendida porque é o entrevistador que, comumente, direciona o desenvolvimento de tal interação, fazendo questionamentos ao entrevistado, conforme já assinalamos anteriormente. Logo, é a partir da ação daquele que busca informações (o entrevistador) que a entrevista é conduzida.

Na compreensão de Marcuschi (1995), ao comentar as noções de assimetria, poder e adequação na interação verbal, as noções de igualdade e desigualdade de condições (de conhecimento e posição social) são traços constitutivos das relações interpessoais na interação verbal. As interações institucionais apresentam diferenças destatus, competênciae responsabilidade. Os papéis, no entanto, são complementares e as responsabilidades também.

Quanto ao modalizador, o enunciado é modalizado pela entonação de ênfase presente no advérbio de inclusão TAMbém, que expressa um caráter de certeza no conteúdo do enunciado. A entonação é um recurso que, entre outras coisas, marca ênfase, imprime uma visão avaliativa, marca uma subjetividade e, assim, o locutor pode influenciar o interlocutor. Portanto, neste enunciado, a entonação imprime asseveração no discurso de L2, gerando um efeito de sentido pautado na certeza de que o referido locutor já passou por várias áreas da saúde, dentre elas a de radiologia. 
A construção argumentativa da fala de L2 reside, nesse trecho específico, na utilização da ênfase do conteúdo proposicional que evoca dois aspectos: primeiro, L2 retoma as palavras de L1 pela área de radiologia TAMbém; segundo, L2 inclui uma nova experiência profissional entre aquelas já citadas, por meio da modalização de entonação presente no advérbio de inclusão TAMbém.

$\mathrm{Na}$ construção da entrevista, o jogo dialógico entre os participantes é construído através de recursos linguísticos, entoações, ênfases, gestos etc. Os modalizadores epistêmicos asseverativos, com frequência, são os recursos linguísticos que marcam a interação entre esses participantes. A próxima ocorrência deixa isso evidente.

\section{MEA22-EE01-Linhas 203-207}

L1 então... como que o senhor lidaria por exemplo na disciplina de radiologia
veterinária nessa nessa questão... pra esses alunos desse universo MUIto variado que
nós temos aqui no Pronatec?
L2 não isso é:: é complicado MESmo... eu tive um choque realmente quando comecei
a lecionar pra o ensino superior...

Verificamos nesse trecho da EE01, que L2, ao ser questionado sobre como lidar com os alunos do PRONATEC, assegura que considera complicado MESmo trabalhar com tal perfil. E, para não deixar margem para dúvidas, em seu enunciado assume que teve um choque realmente, quando iniciou a sua atuação como docente na graduação. Assim, L2 assume um posicionamento de engajamento com o que anuncia, tanto através da entonação destacada no modalizador asseverativo MESmo como em relação ao termo realmente. Os termos em destaque imprimem um encadeamento do caráter asseverativo marcado na fala de L2.

Ademais, percebemos a função argumentativa e interativa da expressão é complicado MESmo, pois esta estabelece um acordo com os dizeres de L1. Esse acordo é fundamental para a construção argumentativa por parte de L2. Seguindo o percurso argumentativo, L2 reforça a afirmação feita por L1 de que o PRONATEC é composto por um universo muito variado de alunos: eu tive um choque realmente quando comecei a lecionar pra o ensino superior....Temos aqui, portanto, um asseverativo que avalia e assevera a fala do outro, mantendo, desse modo, o diálogo entre os interlocutores.

Além disso, a alternância dos falantes não apenas cria os limites precisos do enunciado, mas marca uma relação de acordo, pois, 
V. 9 (1)

287-302

jan-abr 2019

geralmente, L2 tende a concordar com as colocações de L1, já que esse acordo é necessário para que L2 alcance o objetivo pretendido: ser aprovado na entrevista de seleção de emprego. Ocorrências como essas revelam marcas linguísticas do engajamento discursivo entre interlocutores no processo de construção da entrevista de seleção de emprego.

No próximo exemplo, L1 avalia sua própria fala, classificando o conteúdo de sua proposição como fato. Vejamos a ocorrência:

\section{MEA60- EE05-Linhas 132-133}

[...] L1 bom... a escola técnica... ela também... é:: uma porta de entrada pra TOdo o
resto da instituição... isso é FAto e...

Ao afirmar que a escola técnica é também uma porta de entrada para que o docente tenha acesso aos demais setores da universidade, L1 põe força na asseveração por meio do modalizador isso é FAto, que confere ao enunciado o valor de verdade. É a entonação da fala que marca a direção interativa entre entrevistador e entrevistado. Ela é o recurso de ênfase, que imprime nesse enunciado uma visão avaliativa com noção de certeza e marca uma subjetividade na troca comunicativa entre interlocutores.

Ao apresentar o próprio comentário como fato (e não como possibilidade), L1 se compromete com o conteúdo da informação repassada para L2, ao assegurar que a escola técnica é uma porta de entrada pra todo o resto da instituição e, com isso, coloca como certo que L2 também terá oportunidade de acessar outras unidades na instituição, tais como atuar na graduação, na pós-graduação assim como assumir coordenações.

Na perspectiva dos postulados ducrotianos, o trecho em análise não é argumentativo apenas pelas informações que apresenta, ou seja, pelo seu conteúdo informativo. É a presença, a seleção de certas expressões ou termos, como isso é Fato, que produz a orientação argumentativa do enunciado, levando o interlocutor (no caso, L2) a acreditar naquilo que é dito por L1. Além disso, fica claro que o tom de firmeza expresso por L1 constrói positivamente a imagem da instituição. Isso tudo ocorre por meio da linguagem e nesse trecho fica marcado pelo uso de modalizadores asseverativos.

Ao lançar mão de modalidades, portanto, o locutor marca um posicionamento em relação ao enunciado. Segundo Koch (2011), a partir dos modalizadores, o locutor se coloca com relação ao enunciado que produz. O locutor marca "seu maior ou menor grau de engajamento com relação ao que é dito, determinando o grau de tensão que se estabelece entre os interlocutores", explica Koch (2011, p. 85). 
Na mesma linha, Nascimento (2010) assinala que a modalização é uma ação de linguagem que realizamos e que essas ações estão sempre permeadas por intenções e argumentatividade. Dessa forma, a modalização se apresenta como uma "teoria que explica como o locutor deixa registrado, no seu discurso, marcas de sua subjetividade através de elementos linguísticos e, portanto, imprime o modo como esse discurso deve ser lido" (NASCIMENTO, 2010, p. 37).

Ao concebermos os modalizadores como marcadores não somente da subjetividade, mas também da intersubjetividade da linguagem, estamos levantando o véu que revela como a língua marca a ação argumentativa do locutor por meio de elementos linguísticos nas interações sociais as mais diferentes possíveis. Os comentários avaliativos marcados por meio dos modalizadores asseverativos imprimem, portanto, um ponto no discurso em que se fazem perceber a subjetividade e a intersubjetividade.

$\mathrm{Na}$ ocorrência seguinte constatamos um modalizador epistêmico asseverativo marcado por meio da repetição da palavra tenho. Na entrevista, esse modalizador exerce uma função relevante na construção argumentativa do discurso de L2.

\section{MEA40 - EE03-Linhas 86-89}

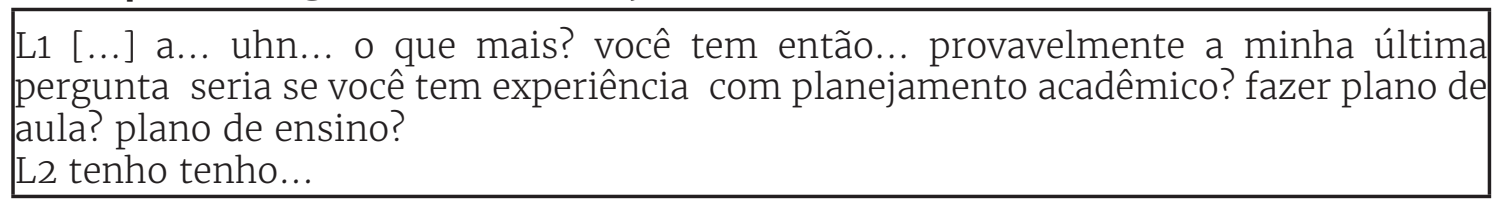

Nesse trecho, L1 pergunta a L2 se este tem experiência com a elaboração de planejamento de aula, ou seja, a orientação discursiva de L1 é a de buscar saber se L2 possui domínio de plano de aula, uma vez que essa é uma das exigências para atuar como docente naquela instituição. L2 prontamente responde, utilizando o recurso da repetição, que é, segundo Koch (2010), um recurso do texto falado e pode desempenhar diversas funções. No caso em tela, a função exercida é a de asseveração, ou seja, a modalização asseverativa, nesse enunciado, se materializa pela repetição da palavra tenho. Assim, L2 assume uma posição de compromisso com o dito, conferindo precisão ao conteúdo do seu enunciado.

Essa certeza explicitada por L2 tem base no conhecimento, pois ele assegura que sabe elaborar plano de aula. E, por isso, lança mão do modalizador epistêmico asseverativo tenho tenho, para dar ênfase ao conteúdo do enunciado, transmitindo segurança para L1, em relação ao domínio que detém com o trabalho de planejar aulas. 
V. 9 (1)

287-302

jan-abr 2019

A repetição em análise não é apenas uma simples característica da fala, mas um recurso argumentativo importante. Ela faz com que L2 responda às perguntas: [...] você tem experiência com planejamento acadêmico? plano de aula? plano de ensino? e, ao mesmo tempo, afirme, reforce e enfatize as repostas dadas. Assim, seguindo a linha de interpretação postulada por Ducrot (1988), é a própria presença ou seleção da forma linguística que produz o movimento argumentativo.

\section{Considerações finais}

Recuperando o objetivo proposto para este estudo - investigar o funcionamento argumentativo dos modalizadores epistêmicos asseverativos na construção do gênero entrevista de seleção de emprego -, pudemos constatar conforme as análises, que esse tipo de modalizador foi empregado pelos locutores para, principalmente, imprimir asseveração ou noção de certeza, ou ainda para dar ideia de credibilidade ao dito, sempre comprometendo os locutores com relação ao conteúdo do enunciado.

Considerando o funcionamento desse recurso, percebemos um comprometimento tanto por parte do entrevistador quanto por parte do entrevistado em relação ao dito. Esse comprometimento fica marcado nos discursos dos locutores quando esses assumem suas posições em relação ao que enunciam. Tais posicionamentos deixam claro de que forma os locutores querem que o dito seja interpretado, ou seja, não há, segundo seus julgamentos, quaisquer dúvidas sobre o que estão expondo.

Os dados revelaram ainda que os modalizadores epistêmicos asseverativos foram proferidos pelo Entrevistador (L1), para principalmente, expressar uma imagem positiva da Unixy, uma vez que esta proporciona oportunidade de progressão para os docentes. Na fala do Entrevistado (L2), tais recursos foram utilizados para transparecer uma imagem positiva do perfil profissional, uma vez que imprime, nos relatos, intenso envolvimento com a área técnica pautado na experiência profissional já adquirida ao longo da carreira docente.

Ademais, os modalizadores epistêmicos asseverativos produziram na entrevista de seleção de emprego, o efeito argumentativo de precisão e de certeza, pois foram usados pelos locutores como recurso para orientar o sentido dos enunciados, bem como com o intuito de tentar convencer tanto (L1) quanto (L2) dos seus pontos de vista e obter 
a aceitação destes. Assim, os locutores recorreram a esses modalizadores do eixo do conhecimento para imprimir força à asseveração e conferir autoridade ao discurso, manifestando alto grau de adesão em relação ao que é proferido na entrevista.

Podemos assegurar, com base nas análises empreendidas, que o modalizador epistêmico asseverativo, no corpus estudado, fica marcado no enunciado quando o locutor qualifica explicitamente seu comprometimento, evidencia a fonte do que se diz, expressa uma avaliação sobre o caráter de certeza da proposição apresentando precisão sobre a natureza epistêmica da proposição a fim de atingir propósitos específicos, quais sejam: de um lado, convencer o entrevistado ao repassar uma imagem positiva da instituição recrutadora; e do outro, convencer o entrevistador sobre as competências e habilidades, a fim de obter aprovação na seleção.

Por fim, os efeitos de sentido foram gerados não só pela utilização de determinadas palavras e expressões que imprimem o caráter de certeza no/do enunciado, mas também pelo recurso da entonação de ênfase e pelo recurso da repetição, os quais funcionaram como modalizadores asseverativos em alguns enunciados proferidos pelo entrevistador (L1) e pelo entrevistado (L2).

\section{Referências}

ADELINO, F.J.S. Na trilha dos modalizadores: perscrutando os jogos argumentativos no gênero entrevista de seleção de emprego. Tese (Doutorado). 332f. Universidade Federal da Paraíba. João Pessoa, 2016.

CASTILHO, A.T.; CASTILHO, C. M. M de. Advérbios Modalizadores. In: ILARI, R. (Org.). Gramática do Português Falado. 2. ed. Campinas, SP: Editora da UNICAMP, 2002, p. 199-247.

CHIAVENATO, I. Recursos Humanos: O capital humano das organizações. 8. ed. São Paulo: Atlas, 2004

DUCROT, O. Polifonia e argumentação: Conferencía del Seminário Teoria de la Argumentación y Analisis del Discurso. Cali: Universidad del Valle, 1988.

ESPÍNDOLA, L. C. A entrevista: um olhar argumentativo. João Pessoa: EDUFPB, 2004.

FÁVERO, L. L. A entrevista na fala e na escrita. In: PRETI, Dino. (Org.) Fala e escrita em questão. São Paulo: Humanitas, 2000, p. 79-96.

KOCH, I. G. V. A inter-ação pela linguagem. 10. ed. São Paulo: Contexto, 2010. KOCH, I. G. V. Argumentação e Linguagem. 13. ed. São Paulo: Cortez, 2011. 
V. 9 (1)

287-302

jan-abr 2019

LYONS, J. Semantics. Cambridge: Cambridge University Press, 1977.

LODI, J. B. A entrevista: teoria e prática. 8. ed. São Paulo: Pioneira, 1991.

MARCUSCHI, L. A. Produção Textual, Análise de Gêneros eCompreensão. São Paulo: Parábola Editorial, 1998.

MARCUSCHI, L. A. Assimetria, poder e adequação na interação verbal. Investigações: linguística e teoria literária. Recife, v. 5, p. 80-93, dez, 1995 .

NASCIMENTO, Erivaldo Pereira do. A modalização deôntica e suas peculiaridades discursivas. Fórum Lingüístico. Florianópolis, v. 7, n. 1, p. 30-45, jan-jun 2010.

NASCIMENTO, E. P. do; SILVA, J. M. da. O fenômeno da modalização: estratégia semântico-argumentativa e pragmática. In: NASCIMENTO, E. P. do (Org.). A argumentação na redação comercial e oficial: estratégias semântico-discursivas em gêneros formulaicos. João Pessoa: Editora da UFPB, 2012. p. 63 - 100.

PALMER, F. R. Mood and modality. Cambridge: Cambridge University Press, 2001. 